\title{
Novel arylpyrazole compounds selectively modulate glucocorticoid receptor regulatory activity
}

\author{
Jen-Chywan Wang, ${ }_{1}^{1}$ Nilesh Shah, ${ }^{1,2,3}$ Carlos Pantoja, ${ }^{1,4}$ Sebastiaan H. Meijsing, ${ }^{1}$ Joseph D. Ho, ${ }^{5}$ \\ Thomas S. Scanlan, ${ }^{1,2}$ and Keith R. Yamamoto ${ }^{1,6}$ \\ ${ }^{1}$ Department of Cellular and Molecular Pharmacology, ${ }^{2}$ Department of Pharmaceutical Chemistry, ${ }^{3}$ Graduate Group of \\ Biophysics, ${ }^{4}$ Graduate Program in Biological Sciences, ${ }^{5}$ Graduate Program in Chemistry and Chemical Biology, University of \\ California, San Francisco, San Francisco, California 94107-2280, USA
}

The activities of intracellular receptors are regulated by their cognate ligands. Here we show that a series of related arylpyrazole compounds, which specifically bind the glucocorticoid receptor (GR), selectively modulated GR-regulated biological functions in preadipocyte, preosteoblast, and lung epithelial cell lines. Indeed, when we monitored 17 endogenous GR target genes in one of these cell types, we found that distinct arylpyrazole compounds induced different expression patterns. We showed by chromatin immunoprecipitation that the arylpyrazole compounds regulated, in a gene-specific manner, either GR occupancy of the genomic glucocorticoid response element (GRE) or events after GR association, such as histone modification. Overall, our results establish that subtle differences in ligand chemistry can profoundly influence the transcriptional regulatory activity of GR, and that endogenous genes bearing natural GREs are especially sensitive detectors of these differences.

[Keywords: Glucocorticoid receptor; glucocorticoid receptor ligand; arylpyrazole compounds; response element; chromatin immunoprecipitation]

Supplemental material is available at http://www.genesdev.org.

Received December 13, 2005; revised version accepted January 18, 2006.

Glucocorticoids are steroid hormones that exert their biological functions through the intracellular glucocorticoid receptor (GR). GR is a transcriptional regulator that, upon binding to cognate ligands, occupies specific genomic glucocorticoid response elements (GREs) and modulates the transcription of nearby genes (Yamamoto 1985, 1995).

Based on conventional views, physiological ligands such as cortisol and corticosterone, and synthetic compounds such as dexamethasone and prednisolone, are agonists that promote the biological functions of GR, whereas ligands such as RU486 are antagonists that bind to GR but inhibit its functions. It is now apparent, however, that ligand activities are strongly context dependent. For example, selective estrogen receptor modulators (SERMs), such as tamoxifen and raloxifene, are agonist-like or antagonist-like in different tissues, and modulate distinct subsets of ER target genes in a given cell type (Shang and Brown 2002; Jordan 2004; Kian Tee

${ }^{6}$ Corresponding author.

E-MAIL yamamoto@cmp.ucsf.edu; FAX (415) 476-6129.

Article and publication are at http://www.genesdev.org/cgi/doi/10.1101/ gad.1400506. et al. 2004); selective ligands for FXR have also been reported (Downes et al. 2003). Accordingly, the definitions of agonist and antagonist are relative to particular phenotypes or specific subsets of target genes, and therefore it is likely that any ligand could act as either agonist or antagonist depending on the context.

Glucocorticoids are among the most effective agents for treating asthma, arthritis, and autoimmune diseases because of their potent anti-inflammatory and immunosuppressive effects. However, chronic systemic glucocorticoid therapy also produces deleterious side effects, including diabetes mellitus, onset of hypertension, weight gain, muscle atrophy, and osteoporosis (Schacke et al. 2002). Therefore, one of the main challenges in glucocorticoid pharmacology is to develop agents that can dissociate anti-inflammatory and immunosuppressive effects from these side effects. One approach was suggested by the notion that GR confers anti-inflammatory effects by transcriptional repression, whereas the side effects reflect transcriptional activation by GR (Rosen and Miner 2005). However, it has been shown that some glucocorticoid-activated genes, such as annexin I, are important in the anti-inflammatory effect (Perretti et al. 2002; Roviezzo et al. 2002), whereas some 
Wang et al.

glucocorticoid-repressed genes, such as endothelial nitric oxide synthase (eNOS) (Wallerath et al. 1999, 2004; Schafer et al. 2005), are associated with deleterious side effects. Therefore, the ideal compounds would display a more complex profile: They would selectively regulate anti-inflammatory genes, leaving the "side-effect" genes unaffected. Unfortunately, the genes that are responsible for the unwanted side effects have not been identified. Moreover, the selectivity by which GR ligands modulate the transcriptional activities of genomic target genes has not been investigated.

Shah and Scanlan (2004) described methods to synthesize novel arylpyrazole compounds that are ligands for GR. They studied 15 of these compounds, each carrying a different adduct at only a single position on the arylpyrazole backbone. The binding affinities of these compounds are similar to those of dexamethasone, prednisolone, and the physiological glucocorticoid, cortisol. All but one of the compounds was able to activate the expression of transfected reporter genes bearing synthetic simple GREs (Shah and Scanlan 2004). In this report, we used these structurally related compounds as tools to examine ligand selectivity in regulating the transcription of primary GR target genes in their normal chromosomal settings. Our strategy was to first investigate whether these compounds selectively modulate GR-regulated biological phenotypes in different cell types. We then determined whether these compounds induced differential gene expression programs in a given cell type, and tested by chromatin immunoprecipitation (ChIP) whether the selective ligand effects correlated with GR occupancy at the target gene GREs.

\section{Results}

Arylpyrazole compounds differentially affect GR-regulated proliferation and differentiation

Table 1 shows the chemical structures of the arylpyrazole compounds used in this study. Notably, the compounds differ only in the substituents attached at "C-11" of the arylpyrazole nucleus, a position thought to be equivalent to C-11 in the C-ring of the steroid nucleus (see dexamethasone structure in Table 1 inset for comparison). In every case, the compounds were bound by the closely related androgen receptor (AR) and progesterone receptor (PR) with affinities at least 100-fold lower than GR (Table 1). Similarly, the compounds failed to trigger transcriptional activation by the mineralocorticoid receptor (MR), cotransfected into CV-1 cells with a reporter gene bearing multiple mineralocorticoid response elements, whereas GR was strongly activated in parallel assays (data not shown). Thus, this series of arylpyrazoles is highly selective for GR.

We then tested the biological effects of these compounds in three glucocorticoid-responsive cell types. First, we examined the effects of a saturating concentration $(1 \mu \mathrm{M})$ of the compounds in A549, a human lung epithelial cell line that responds strongly to proinflam-
Table 1. GR ligands

(12)

matory signals, and, as with many cells involved in inflammatory responses, is growth inhibited by dexamethasone and prednisolone (Fig. 1A). To monitor cell viability and proliferation, we measured relative ATP levels in cells treated with the various compounds; ATP can be measured sensitively, rapidly, and precisely, and correlates closely with $\left[{ }^{3} \mathrm{H}\right]$-thymidine incorporation assays (Crouch et al. 1993). We found that ligand 2 was comparable to dexamethasone and prednisolone in suppressing cell proliferation, whereas ligands 1, 3, 4, 6-12, and $\mathbf{1 4}$ had weaker effects; notably, this assay is highly sensitive, such that even the weak effects reflect significant activity. In contrast, ligands 5, 13, and 15 had no effect (Fig. 1A).

Next, we tested the compounds in mouse 3T3-L1 prea- 
A.

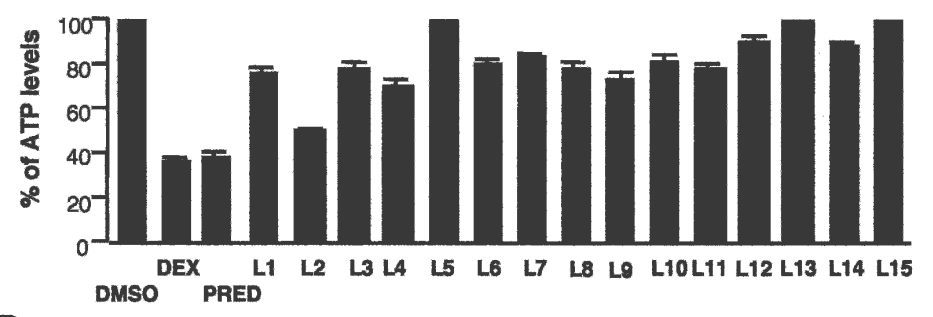

B.

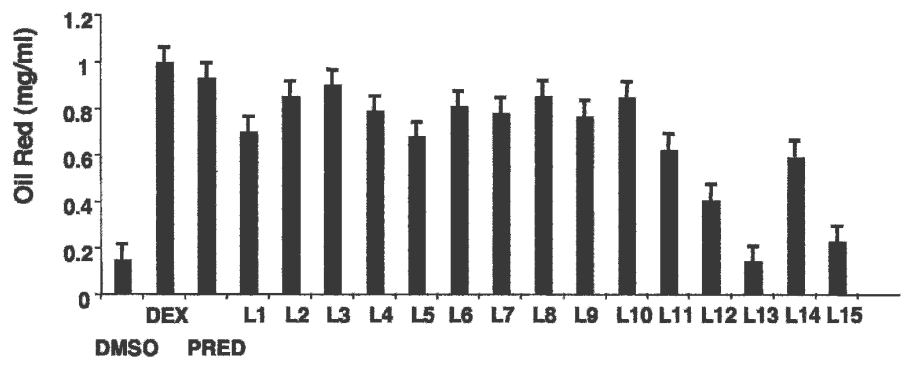

C.

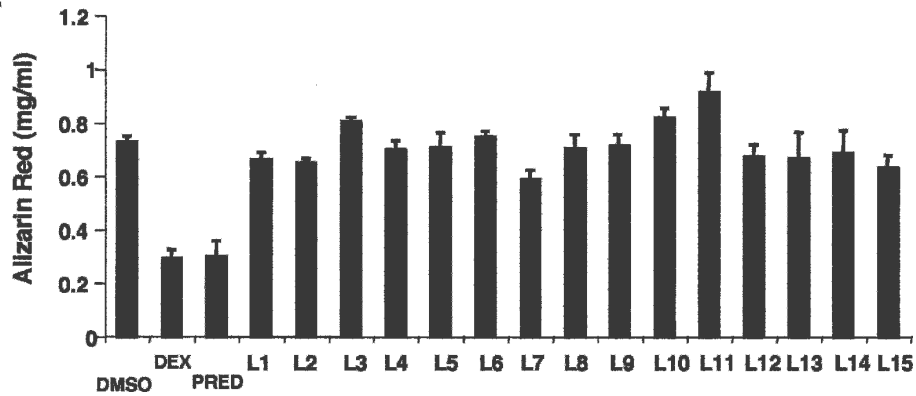

Figure 1. Arylpyrazole compounds differentially affect cell growth and differentiation. (A) Effects of arylpyrazole compounds on A549 cell proliferation. A549 cells were treated with either DMSO, dexamethasone 10.1 $\mu \mathrm{M})$, or arylpyrazole compounds $(1 \mu \mathrm{M})$ for $5 \mathrm{~d}$, and the relative ATP levels were measured. The data represent the mean (standard error of the mean, SEM) of the percent of ATP levels (dexamethasone or arylpyrazole compound-treated divided by the DMSO-treated) from four experiments. (B) Effects of arylpyrazole compounds on 3T3-L1 adipocyte differentiation. Confluent cultures of 3T3-L1 cells were placed in differentiation medium that contained IBMX, insulin with either DMSO, dexamethasone $(1 \mu \mathrm{M})$, prednisolone $(1 \mu \mathrm{M})$, or various arylpyrazole compounds $(1 \mu \mathrm{M})$ as indicated. Oil Red staining was used to measure the extent of adipocyte differentiation. The data represent the mean (SEM) of Oil Red concentration from three experiments. $(C)$ The effects of arylpyrazole compounds on MC3T3-E1 osteoblast differentiation. MC3T3-E1 cells were grown to confluence and then placed in differentiation medium that contained either DMSO, dexamethasone $(1 \mu \mathrm{M})$, prednisolone $(1 \mu \mathrm{M})$, or various arylpyrazole compounds $(1 \mu \mathrm{M})$ as indicated. Alizarin Red staining was used to measure the extent of osteoblast differentiation. Data are averaged (with SEM) from four independent experiments. dipocytes, where dexamethasone, insulin, and IBMX act together to drive adipocyte differentiation. We assessed the ability of the arylpyrazole compounds to replace dexamethasone in the differentiation cocktail. As shown in Figure 1B, most compounds (at $1 \mu \mathrm{M}$ ) were able to substitute for dexamethasone to induce differentiation. The effects of ligands $\mathbf{2 - 4}$ and $\mathbf{6 - 1 0}$ were similar to those of dexamethasone, whereas ligands 1, 5, 11, and 14 had weaker effects. Three compounds-ligands 12, 13, and 15-did not induce 3T3-L1 differentiation (Fig. 1B). Notably, this pattern of ligand effects differed substantially from the pattern of effects of observed in A549 cells.

Finally, we determined the actions of the compounds in mouse MC3T3-E1 preosteoblasts, where dexamethasone and prednisolone inhibit differentiation to osteoblasts (Fig. 1C; Luppen et al. 2003; Leclerc et al. 2004). Strikingly, none of the compounds inhibited MC3T3-E1 preosteoblast differentiation as measured by alizarin red staining (Fig. 1C). When we monitored the levels of calcium and phosphate, two indicators of osteoblast differentiation, ligands 2 and $\mathbf{9}$, had modest effects (data not shown). Again, this pattern of ligand effects differed markedly from the patterns observed in A549 or 3T3-L1 cells. Thus, the various arylpyrazole compounds clearly function differentially in different cell types (Table 2).
For example, ligand 2 induced 3T3-L1 differentiation and inhibited A549 cell proliferation but did not efficiently suppress MC3T3-E1 differentiation.

\section{Distinct arylpyrazole compounds induced differential gene expression patterns in a single cell type}

The selective functions of distinct ligands in different cell types suggested that each arylpyrazole compound may regulate a specific gene expression program. In order to test this model, we compared the gene expression profiles regulated by arylpyrazole compounds in a single cell type. A549 cells were chosen because dexamethasoneresponsive genes had already been defined by microarray analysis, and $>10$ of these had been shown to be primary regulatory targets, as defined by demonstration of GR occupancy in vivo at the GREs of each gene (Wang et al. 2004); in contrast, few primary GR target genes have been identified in 3T3-L1 and MC3T3-E1. A549 cells express functional GR and display characteristics of type II alveolar epithelial cells, which are glucocorticoid target cells in vivo; regulation of various primary GR target genes, such as those involved in sodium transport and lung homeostasis $(\mathrm{ENaC} \alpha)$, cell proliferation (Kip2), and the inflammatory response (IL-8 and GM-CSF), has been studied in these cells (Chow et al. 1999; Ito et al. 2000; 
Table 2. Comparison of biological effects of arylpyrazole compounds in three cell types

\begin{tabular}{lccc}
\hline & $\begin{array}{c}\text { Inhibition of A549 } \\
\text { cell proliferation }\end{array}$ & $\begin{array}{c}\text { Induction of 3T3-L1 } \\
\text { preadipocyte differentiation }\end{array}$ & $\begin{array}{c}\text { Repression of MC3T3-E1 } \\
\text { preosteoblast differentiation }\end{array}$ \\
\hline Dexamethasone & ++ & ++ & ++ \\
L1 & + & + & -- \\
L2 & ++ & ++ & -- \\
L3 & + & ++ & -- \\
L4 & + & ++ & -- \\
L5 & -- & + & -- \\
L6 & + & ++ & -- \\
L7 & + & ++ & -- \\
L8 & + & ++ & -- \\
L9 & + & ++ & -- \\
L10 & + & + & -- \\
L11 & + & -- & -- \\
L12 & + & -- & -- \\
L13 & -- & + & - \\
L14 & + & -- & - \\
L15 & -- & & - \\
\hline
\end{tabular}

Nissen and Yamamoto 2000; Wang et al. 2000; Alheim et al. 2003; Luecke and Yamamoto 2005).

We chose 17 representative A549 GR target genes and used quantitative real-time PCR (qPCR) to compare gene expression patterns induced by arylpyrazole compounds, dexamethasone, and prednisolone. These 17 genes were selected because they are highly regulated by glucocorticoids and/or their GREs were previously identified. As shown in Figure 2, A-C, the different arylpyrazole compounds induced distinct patterns of gene expression. For example, ligands 2, 4, 8-12, and $\mathbf{1 4}$ activated all of the genes that were activated by dexamethasone; ligand 2 showed the strongest activities among these compounds (Fig. 2A). In contrast, ligands $\mathbf{1}$, 3, and 5-7 induced only a subset of the dexamethasoneinduced genes, and ligand $\mathbf{1 5}$ did not activate any target gene (Fig. 2A).

Glucocorticoids act as potent anti-inflammatory agents by suppressing the expression of various cytokine and chemokine genes. We tested the effects of our arylpyrazole compounds on six cytokines whose expression is induced by TNF- $\alpha$ (Fig. 2B). We found that ligands 1, 2, and 4 inhibited the expression of most of the TNF- $\alpha$ induced genes, whereas ligands 12-15 had little effect (Fig. 2A). Ligands $\mathbf{3}$ and 6-10 inhibited only a subset (two or three) of the genes (Fig. 2B); in contrast, ligand 5, which induced only a single target gene of our test set, repressed three of the cytokine genes, although the effect was relatively modest (Fig. 2B). Furthermore, the six TNF- $\alpha$-regulated genes could be divided into two groups with respect to their responses to ligands 6-10: MCP-1, GM-CSF, and IL-6 were somewhat inhibited, whereas IL-8, RANTES, and GRO1 were largely unaffected (Fig. 2B).

The final group of target genes in our test set was glucocorticoid-repressed but not TNF $\alpha$-induced. Ligands $\mathbf{1}$, 2, 4, and $\mathbf{6}$ generally mimicked the effects of dexamethasone and prednisolone on these four genes; ligands 3 and
7 repressed two target genes; ligands $\mathbf{5}$ and $\mathbf{8 - 1 1}$ inhibited only one; and ligands $\mathbf{1 2 - 1 5}$ failed to repress (Fig. 2C). Interestingly, most of the compounds repressed NAV3 gene expression, but only ligands 1-3 repressed GEM, and then only weakly (Fig. 2C).

In summary, our results showed that modest changes in ligand chemistry can cause dramatic effects on gene expression profiles. Strikingly, when these same $15 \mathrm{com}-$ pounds were tested for regulation of a transfected reporter gene containing synthetic GREs in A549 cells, all but ligand 13 activated transcription, although ligands 5 and 15 were weaker than the others (Fig. 2D). Thus, the differential effects of modest changes in ligand chemistry are greatly amplified in the context of natural response elements in their normal chromosomal settings.

Ligand $\mathbf{1 5}$ is a competitive inhibitor of prednisolone and dexamethasone effects

As ligands 13 and 15 bound GR with high affinities in vitro (Table 1), yet failed to regulate any glucocorticoid-responsive genes or influence A549 cell growth, we tested whether they potentiate GR activities prior to changes in gene expression, such as nuclear localization. Cells that stably express rat GR fused to enhanced GFP (eGFP-rGR) were treated with DMSO, dexamethasone, and ligand $\mathbf{1 3}$ or ligand $\mathbf{1 5}$ for $4 \mathrm{~h}$, and the localization of eGFP-rGR was monitored. As shown in Figure 3A, eGFP-rGR was cytoplasmic in the control (DMSO-treated) cells and nuclear in the dexamethasone-, ligand 13-, or ligand 15-treated cultures (Fig. 3BD). Thus, these experiments demonstrate that ligands $\mathbf{1 3}$ and $\mathbf{1 5}$ differ from dexamethasome in their effects on GR function at some step after ligand binding and nuclear localization.

We then tested whether these two compounds are competitive inhibitors of dexamethasone and predniso- 
A.

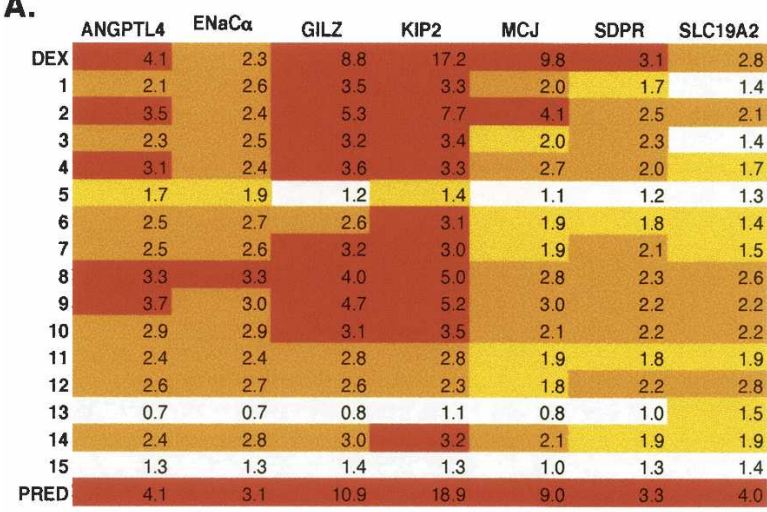

C.

\begin{tabular}{r|rrrrr} 
& \multicolumn{1}{l}{ SNK } & BHLHB2 & \multicolumn{1}{l}{ GEM } & \multicolumn{1}{l}{ NAV3 } \\
\hline DEX & 64.2 & 47.6 & 51.5 & 81.8 \\
$\mathbf{1}$ & 50.3 & 40.8 & 26.5 & 63.0 \\
$\mathbf{2}$ & 59.0 & 48.3 & 31.0 & 76.8 \\
$\mathbf{3}$ & 18.8 & 25.0 & 21.0 & 48.0 \\
$\mathbf{4}$ & 30.5 & 29.5 & 0.0 & 50.0 \\
$\mathbf{5}$ & 26.2 & 15.8 & -11.5 & 17.0 \\
$\mathbf{6}$ & 52.0 & 26.8 & 6.5 & 51.0 \\
$\mathbf{7}$ & 22 & 28.0 & 16.0 & 46.8 \\
$\mathbf{8}$ & 17.8 & 8.0 & 9.5 & 33.2 \\
$\mathbf{9}$ & 25.4 & 14.4 & -1.0 & 45.2 \\
$\mathbf{1 0}$ & 22.75 & 16.8 & -3.5 & 47.4 \\
$\mathbf{1 1}$ & 11.8 & 14.8 & 12.0 & 30.6 \\
$\mathbf{1 2}$ & 2.4 & 13.2 & -27.5 & 25.0 \\
$\mathbf{1 3}$ & -64.5 & -8.8 & -51.0 & -96.0 \\
$\mathbf{1 4}$ & 2.06 & 5.3 & -14.0 & 19.2 \\
$\mathbf{1 5}$ & 6.7 & 20.0 & -9.5 & -4.8 \\
\hline PRED & 43.5 & 40.8 & 44.5 & 56.8 \\
\hline & & & &
\end{tabular}

B.

\begin{tabular}{rrrrrrrr}
\multicolumn{1}{l}{ IL8 } & RANTES & \multicolumn{1}{c}{ GRO1 } & MCP1 & GM-CSF & \multicolumn{1}{l}{ IL6 } \\
\hline DEX & 64.2 & 67.4 & 45.0 & 74.2 & 64.4 & 86.8 \\
$\mathbf{1}$ & 24.7 & 43.5 & 22.2 & 46.7 & 37.3 & 44.0 \\
$\mathbf{2}$ & 46.7 & 48.0 & 17.1 & 65.7 & 49.0 & 68.3 \\
$\mathbf{3}$ & 30.3 & 31.3 & 11.6 & 48.7 & 21.5 & 41.7 \\
$\mathbf{4}$ & 29.1 & 44.3 & 21.4 & 46.6 & 33.3 & 47.7 \\
$\mathbf{5}$ & 14.9 & 32.3 & 12.8 & 33.7 & 36.5 & 20.7 \\
$\mathbf{6}$ & 5.2 & -5.5 & -9.8 & 30.2 & 24.1 & 34.3 \\
$\mathbf{7}$ & 8.8 & 7.4 & -9.1 & 26.9 & 18.4 & 37.5 \\
$\mathbf{8}$ & 18.1 & 24.3 & 16.2 & 39.2 & 29.4 & 35.3 \\
$\mathbf{9}$ & 22.8 & -8.8 & 8.6 & 42.2 & 34.6 & 29.0 \\
$\mathbf{1 0}$ & 15.9 & 2.6 & 4.2 & 31.1 & 18.9 & 34.8 \\
$\mathbf{1 1}$ & 18.1 & 15.4 & -0.2 & 22.6 & 12.6 & 37.5 \\
$\mathbf{1 2}$ & 12.2 & 11.0 & 5.4 & 20.6 & 18.7 & 20.3 \\
$\mathbf{1 3}$ & -21.7 & -35.8 & -25.9 & -19.7 & -11.0 & -4.0 \\
$\mathbf{1 4}$ & 1.0 & -16.2 & 9.0 & 29.1 & 23.6 & 13.5 \\
$\mathbf{1 5}$ & -5.2 & -48.2 & -13.8 & -7.6 & -6.1 & -2.0
\end{tabular}

D.

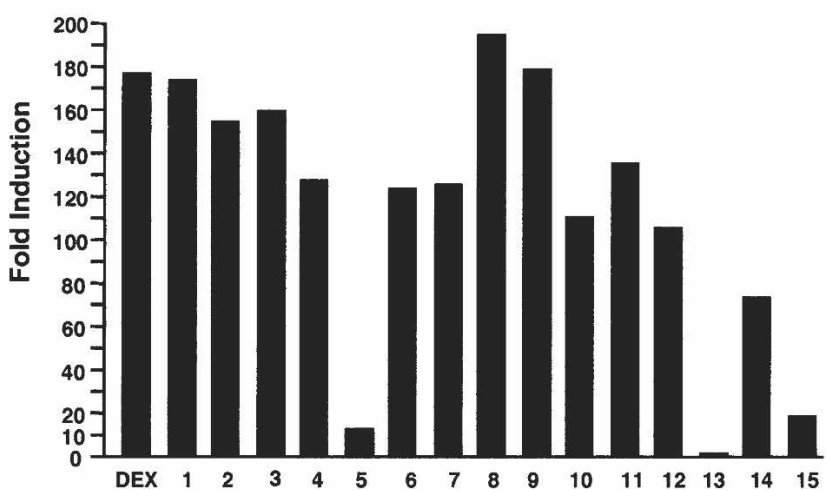

Figure 2. Arylpyrazole compounds differentially affect the expression of GR target genes in A549 cells. (A) Effects of arylpyrazole compounds on dexamethasone-induced genes. A549 cells were treated with dexamethasone or various arylpyrazole compounds for 4-5 h. Total RNA was prepared and subjected to cDNA synthesis. The cDNA was then analyzed by qPCR to measure the relative mRNA levels of distinct target genes using gene-specific primers. Red bars represent induction greater than threefold. Orange represents induction between two- and threefold. Yellow represents induction between 1.5-fold and twofold. (B) Effects of arylpyrazole compounds on TNF $\alpha$-induced dexamethasone-suppressed genes. A549 cells were treated with TNF $\alpha$ and either dexamethasone or arylpyrazole compounds for $4 \mathrm{~h}$. Total RNA was prepared and subjected to cDNA synthesis. The cDNA was then analyzed by qPCR to measure the relative mRNA levels of distinct target genes using gene-specific primers. Green represents percent inhibition $>50 \%$. Medium green represents percent inhibition between $25 \%$ and $50 \%$. Light green represents percent inhibition between $0 \%$ and $25 \%$. (C) Effects of arylpyrazole compounds on dexamethasone-suppressed genes. A549 cells were treated with TNF $\alpha$ and dexamethasone or various arylpyrazole compounds for $4 \mathrm{~h}$. Total RNA was isolated and subjected to cDNA synthesis. The cDNA was then analyzed by qPCR to measure the mRNA levels of distinct target genes. The representative colors are as described above. The data in $A-C$ represent the mean of the fold induction (DEX-treated responses divided by the DMSO-treated responses) from at least three experiments. The SEM is shown in the Supplemental Material. $(D)$ The effects of arylpyrazole compounds on reporter genes containing simple GRE. Seventy-five nanograms of TAT3 reporter plasmids were transfected with $100 \mathrm{ng}$ of RSV- $\beta$ Gal into A549 cells in a $24-w e l l$ plate. After $24 \mathrm{~h}$, cells were washed with PBS and treated with $0.1 \mu \mathrm{M}$ DEX for an additional 16-20 h. Cells were then lysed and subjected to assays for luciferase and $\beta$-Gal activities. One representative data set from three independent transfection experiments is shown.

lone. For these experiments, we cotreated A549 cells with $1 \mu \mathrm{M}$ ligand $\mathbf{1 3}$ or $\mathbf{1 5}$ and 1 or $0.1 \mu \mathrm{M}$ prednisolone, and monitored the effects on GR-responsive genes. As shown in Figure 4A, ligand 15 but not 13 significantly antagonized the $0.1 \mu \mathrm{M}$ prednisolone-induced expression of Kip2, GILZ, and MCJ genes, whereas ligand $\mathbf{1 3}$ had no effect. Ligand $\mathbf{1 5}$ also modestly inhibited the induction of these three genes by prednisolone (Fig. 4A). We further showed that $1 \mu \mathrm{M}$ ligand 15 but not $\mathbf{1 3}$ significantly decreased the antiproliferative effect of $0.1 \mu \mathrm{M}$ prednisolone (Fig. 4B), whereas neither ligand competed with 1 $\mu \mathrm{M}$ prednisolone (Fig. 4B). Taken together, our findings establish that ligand $\mathbf{1 5}$ is a competitive inhibitor of prednisolone in A549 cells.

\section{GR:GRE binding in vivo is differentially regulated by ligands}

The failure of ligands $\mathbf{1 3}$ and $\mathbf{1 5}$ to affect GR target gene transcription could reflect either a loss of GRE occupancy by GR bound to either of these two compounds, or GR:GRE binding by GR that is inactive for transcriptional regulation. To test this model, we performed ChIP assays to detect the in vivo GR occupancy at three 
Wang et al.

A.

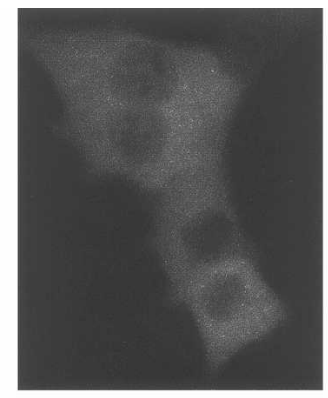

B.

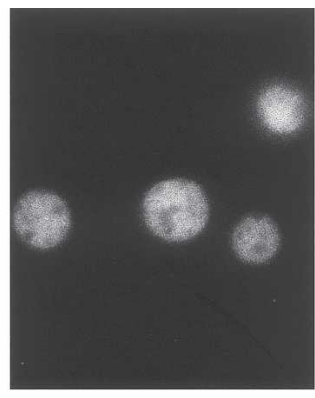

C.

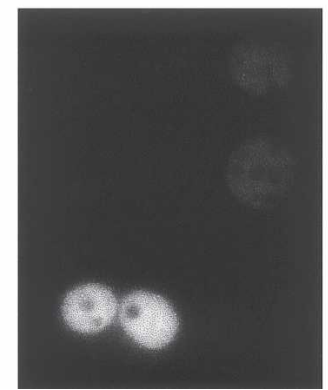

D.

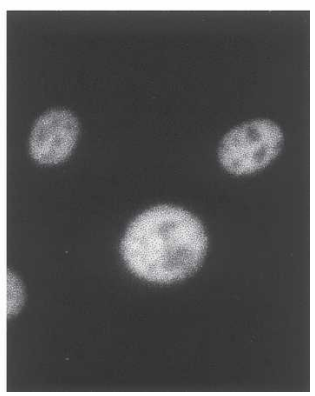

Figure 3. Ligands $\mathbf{1 3}$ and $\mathbf{1 5}$ induce GR nuclear localization. Subconfluent eGFP-rGR cells were treated with DMSO (vehicle control) $(A), 100 \mathrm{nM}$ dexamethasone $(B), 1 \mu \mathrm{M}$ ligand $\mathbf{1 3}(C)$, and $1 \mu \mathrm{M}$ ligand $\mathbf{1 5}(D)$ for $4 \mathrm{~h}$. Localization of eGFP-rGR protein was then monitored. Representative data from two experiments are shown.

GREs: ENaC $\alpha$, GILZ, and SLC19A2 (Wang et al. 2004). We found that ligand 13-bound GR (denoted as GR:13) did not occupy any of these three GREs (Fig. 5A-C). GR:15 was recruited to the GILZ and the SLC19A2 GREs, but the occupancy was lower than that of GR:prednisolone (Fig. 5B,C). Interestingly, the occupancy of GR:15 and GR:prednisolone at $\mathrm{ENaC} \alpha$ GRE was comparable (Fig. 5A), despite the failure of ligand $\mathbf{1 5}$ to activate $\mathrm{ENaC} \alpha$ gene transcription.

A.

GILZ $\square$ KIp2 目MCJ

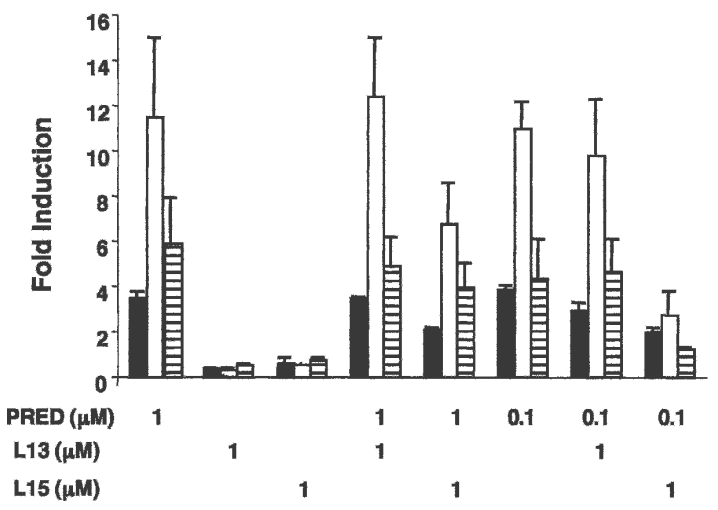

We also tested the occupancy of ligands GR:2, GR:3, and GR:5 at these three GREs. At the ENaC $\alpha$ GRE, the recruitment of GR was comparable when A549 cells were treated with prednisolone or ligands 2, 3, or 5 (Fig. $5 \mathrm{~A}$ ); in parallel, the $\mathrm{ENaC} \alpha$ gene was induced by prednisolone and these three compounds (Figs. 2A, 5A). While the occupancy of GR:2 was comparable to that of GR:prednisolone at the GILZ and the SLC19A2 GREs, the occupancy of GR:5 was much weaker (Fig. 5B,C), and ligand 5 failed to induce transcription of either gene (Fig. 2A). The weaker occupancy of GR:3 relative to GR:prednisolone at the GILZ GRE appeared to correlate with a lower magnitude of induction of GILZ gene expression by ligand 3 (Fig. 5B). In contrast, whereas GR:3 significantly occupied SLC19A2 GRE, it did not activate SLC19A2 gene transcription (Figs. 2A, 4C).

Taken together, our results indicated that GR:GRE occupancy commonly correlated with receptor-mediated induction. Importantly, however, we defined two distinct mechanisms by which ligands selectively regulate GR target gene transcription. First, GR:13 complexes failed to occupy three GREs at genes that are strongly induced by GR:prednisolone. Second, GR:3 and GR:15 occupied successfully the GREs at the SLC19A2 and $\mathrm{ENaC} \alpha$ genes, respectively, but they were inactive in transcriptional regulation, implying a functional difference in the regulatory complexes at these genes at a step downstream of GRE occupancy.

Prednisolone, not ligand 15, induces histone acetylation of the ENaCa gene

Among the first events following GR:GRE occupancy are modifications of chromatin structure, such as histone acetylation. We surveyed the effects of prednisolone and ligand $\mathbf{1 5}$ on histone acetylation of the $\mathrm{ENaC} \alpha$ gene by monitoring eight genomic regions spanning $1.5 \mathrm{~kb}$ on

B.

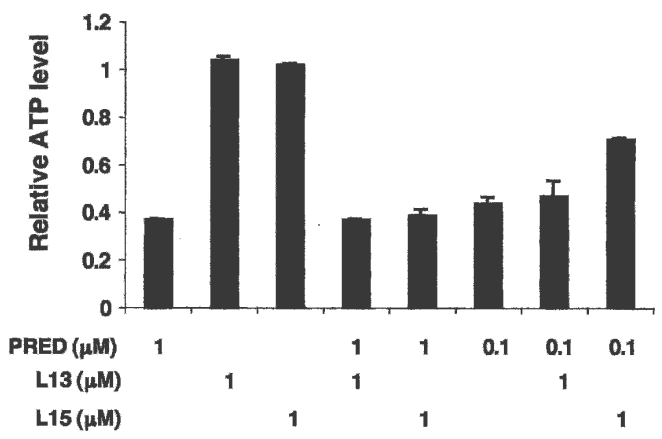

Figure 4. Ligand 15 inhibits prednisolone-regulated cell proliferation and gene expression in A549 cells. (A) A549 cells were treated as indicated for $4-5 \mathrm{~h}$. Total RNA was isolated and subjected to cDNA synthesis. The cDNA was then analyzed by qPCR to measure mRNA levels of distinct GR target genes: GILZ (solid bar), Kip2 (open bar), and MCJ (hatched bar). The data represent the mean (SEM) of the fold induction (relative to DMSO-treated responses) from four experiments. (B) A549 cells were treated with distinct ligands as indicated for $5 \mathrm{~d}$. The relative ATP levels of cells were then measured. The data represent the mean (SEM) of the fold induction (relative to DMSO-treated responses) from three experiments. 
A.

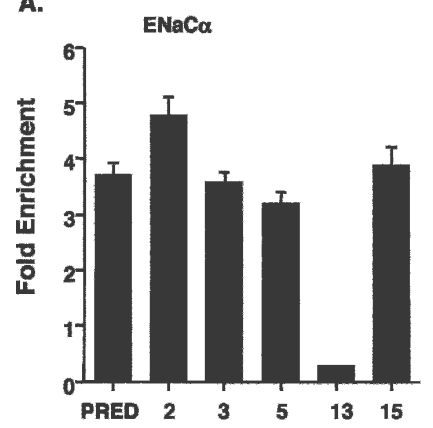

B. GIZ

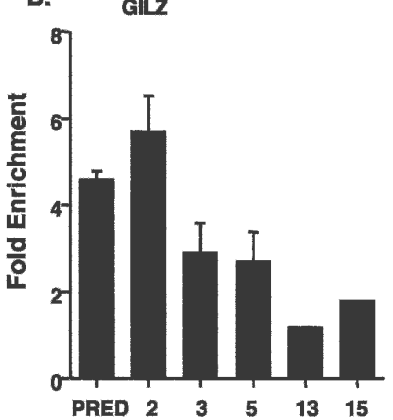

C. SLC19A2

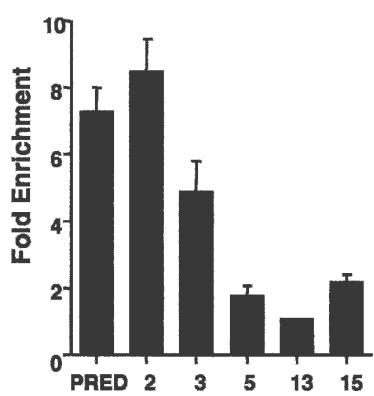

Figure 5. Arylpyrazole compounds differentially affect GR occupancy at distinct GREs. A549 cells were treated with prednisolone or various arylpyrazole compounds for $1 \mathrm{~h}$, and ChIP experiments were performed to assess occupancy by GR. The results for the following genes are shown: $\mathrm{ENaC} \alpha(A), \operatorname{GILZ}(B)$, and SLC19A2 $(C)$. The fold enrichment values for the experimental regions are determined by normalizing to the control hsp70 value. The data represent the mean (SEM) of the fold enrichment (relative to DMSO-treated responses) from at least three experiments.

either side of the transcription start site (Fig. 5A). Timecourse experiments with prednisolone revealed that maximal increases of acetylated histone $\mathrm{H} 3$ and $\mathrm{H} 4 \mathrm{lev}$ els were observed upon $30 \mathrm{~min}$ of treatment in many of these regions (data not shown). For histone H3, prednisolone increased acetylation levels in three genomic regions (Fig. 6B, regions 1, 5, 7, and 8); in contrast, ligand 15 did not increase AcH3 levels in these regions (Fig. 6B). Furthermore, prednisolone increased the levels of acetylated histone $\mathrm{H} 4(\mathrm{AcH} 4)$ in all genomic regions tested except region 3, which includes the GRE (Fig. 6C). Ligand 15, however, failed to induce significant AcH4 levels in these seven regions (Fig. 6C). Overall, these results demonstrated that although GR:15 is recruited to the $\mathrm{ENaC} \alpha \mathrm{GRE}$, it is unable to stimulate efficient histone acetylation.

\section{Discussion}

Previous studies have shown that ligands for various intracellular receptors can dictate the actions of their cog- nate receptors. Most notably, ER ligands such as estradiol, tamoxifen, and raloxifene display distinct functions in different cell types, and induce dramatically different gene expression profiles in a single cell type (Shang and Brown 2002; Jordan 2004; Kian Tee et al. 2004). Although these results are striking, the chemical structures of these ER ligands are significantly different, thus complicating inferences of potential relationships between chemical structure and biological response. In this study, we applied a series of structurally related compounds (Table 1), that differ at only a single position on an arylpyrazole scaffold, to systematically analyze their effects on GR actions.

Our closely related arylpyrazole compounds displayed remarkable differences in their effects on GR target genes (Table 2; Fig. 2B). For example, ligands 14 and 15 differ only in the position of a single hydroxyl group (Table 1); however, they evoked markedly distinct GRregulatory activities, both in A549 and in 3T3-L1 cells. In A549 cells, ligand $\mathbf{1 4}$ effectively induced the expression of several prednisolone-activated genes, whereas li-
A.
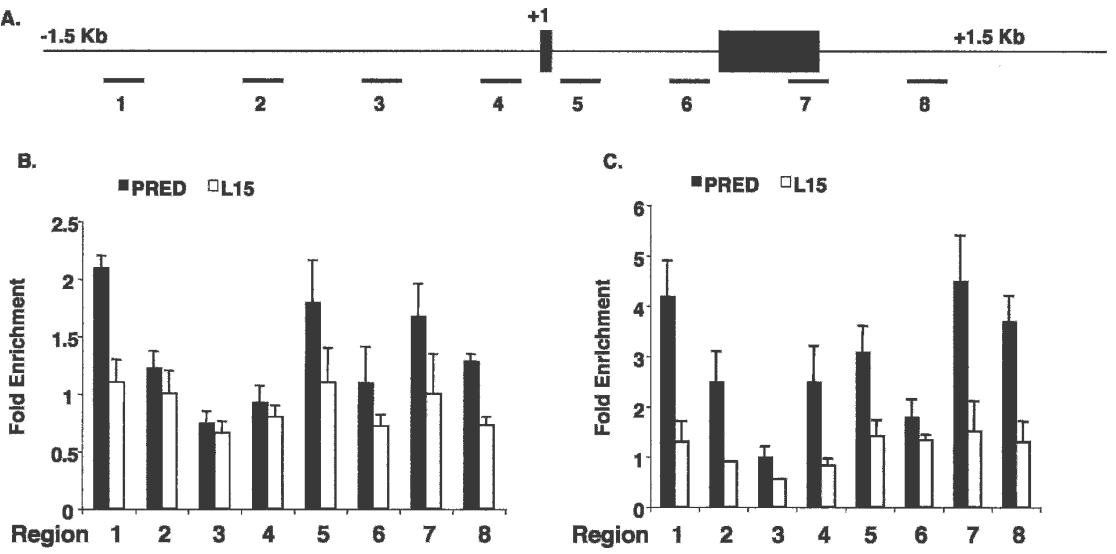

c.

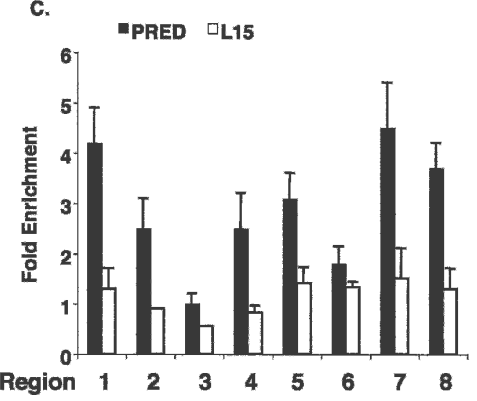

Figure 6. Prednisolone but not ligand $\mathbf{1 5}$ increases histone acetylation at the $\mathrm{ENaC} \alpha$ gene. (A) Schematic diagram of the $\mathrm{ENaC} \alpha$ gene; closed boxes indicate exons, and the transcription start site is indicated as +1 . Amplified genomic regions are underlined and numbered. (B) A549 cells were treated with prednisolone $(1 \mu \mathrm{M})$ or ligand 15 (1 $\mu \mathrm{M}$ ) for $30 \mathrm{~min}$, and actylated histone $\mathrm{H} 3$ was measured in each numbered region by ChIP. (C) A549 cells were treated with prednisolone $(1 \mu \mathrm{M})$ or ligand $15(1 \mu \mathrm{M})$ for 30 min, and actylated histone $\mathrm{H} 4$ was measured in each numbered region by ChIP. Fold enrichment values in $B$ and $C$ were determined by normalizing to a control gene, hsp70. The data represent the mean (SEM) of the fold enrichment (relative to DMSOtreated responses) from at least three experiments. 
gand $\mathbf{1 5}$ failed to activate any. Similarly, ligands $\mathbf{4}$ and 9 differ only by a single oxygen atom, yet ligand 4 represses the Rantes gene nearly as effectively as dexamethasone, whereas ligand 9 is inactive. Thus, our studies demonstrate that slight differences in ligand structure can drastically affect the activities of intracellular receptors; moreover, ligand activities clearly depend on response element and cellular context. By comparing chemically similar ligands in well-defined response element and cellular (or cell-free) environments, it should eventually be possible to discern structure-function relationships for ligands and, in turn, to define how changes in the topology of the ligand-binding pocket determine specific receptor actions.

Our ChIP experiments showed that the different arylpyrazole compounds produced strikingly distinct enrichments of GR-binding fragments from different genes. We have assumed here that the differential enrichments are proportional to GR occupancy in vivo; an alternative explanation is that differential ChIP signals reflect variations in epitope accessibility or affinity resulting from distinct GR conformations or regulatory complex compositions. It may prove possible in future work to distinguish these possibilities, for example, by testing whether the arylpyrazole compounds affect intrinsic GR:GREbinding affinities. Whatever the case may be, our present findings establish that differences in ligand chemistry give rise to a host of functionally distinct GR-containing regulatory complexes. Indeed, these results using synthetic ligands suggest that the conventional idea that GR uses only a single ligand in vivo perhaps should be reevaluated; particular precursors or metabolites of cortisol, for example, may be functional GR ligands in specific cell or gene contexts.

Although our ChIP results generally indicate a rough correspondence between GR:GRE occupancy and the magnitude of regulation, this correspondence is clearly violated at certain GREs. This might be explained in some settings by ligand-selective effects on the actions of GREs as allosteric regulators of GR activity (Lefstin and Yamamoto 1998). In addition, GR-binding sequences associated with normal chromosomal genes are commonly embedded within clusters of factor-binding sites that collectively comprise "composite" GREs. These elements include binding sites for non-GR regulators that participate in a GRE-specific manner in the hormone response. At some composite GREs, such as that for the rat phosphoenolpyruvate carboxykinase (PEPCK) gene, the nonreceptor regulators are required for GR recruitment to its DNA-binding sites (Stafford et al. 2001); at others, such as that for the proliferin gene, GR binds to the GRE independently but depends on nonreceptor regulators to define its activity (Diamond et al. 1990; Miner and Yamamoto 1991). Furthermore, GR also can act from "tethering" GREs, at which the receptor fails to bind DNA, and instead associates through protein-protein interaction with a DNA-bound nonreceptor regulator (Yamamoto 1995; Luecke and Yamamoto 2005). Remarkably, even a 1-base-pair difference in a regulatorbinding site can result in the recruitment of distinct cofactors to regulatory complexes (Leung et al. 2004; Luecke and Yamamoto 2005). In the limit, this implies that each GR target gene might nucleate the assembly of a GRE-specific regulatory complex to mediate its glucocorticoid response; Rogatsky et al. (2003) have, in fact, detected GRE-specific patterns of GR functional domains, each conferring glucocorticoid activation of a different gene.

Thus, GR integrates signaling information from both ligands and GREs to determine its conformation and regulatory function. Notably, because ligand binding precedes the potential GRE interaction, the GR conformation induced by a particular arylpyrazole compound may promote binding to only a subset of GREs, and regulatory activity at only a subset of the occupied sites. In our study, we used dexamethasone to identify an initial set of GR target genes; it seems likely that the arylpyrazole compounds may regulate additional genes not controlled by dexamethasone or prednisolone. Moreover, our initial assays measured the effects of the arylpyrazole ligands on the expression of a reporter gene bearing a simple synthetic GRE. Because each reporter represents only a certain GRE context, reporter analyses greatly oversimplify the ligand effects on endogenous gene regulation. Notably, ligand $\mathbf{1 5}$, which was inactive on several endogenous target genes induced by prednisolone, was able to activate reporter gene expression. Thus, ligand $\mathbf{1 5}$ may in fact regulate a subset of endogenous genes whose GRE sequences and architecture yield functional ligand 15-induced regulatory complexes in appropriate cell contexts in vivo.

Our results indicate that multiple mechanisms underlie ligand-regulated gene transcription. Thus, ligands can differentially affect the capacity of GR to bind to particular GREs. In addition, ligands can selectively affect events downstream of GR:GRE association, such as histone acetylation. In the simplest model, these downstream events may reflect ligand-directed differences in the subunit composition of the regulatory complexes. Alternatively, the complexes may be compositionally identical, but conformationally distinct in ways that affect their specific functions. Interestingly, for the $\mathrm{ENaC} \alpha$ genes we found that p300, a universal coactivator, was recruited to the GRE upon either prednisolone or ligand 15 treatment (data not shown). In future studies, it will be interesting to determine whether the differential effect of these two ligands on GR regulation of EnaC $\alpha$ resides in differences in subunit occupancy or conformation.

In conclusion, we suggest that subtle differences in ligand structure induce or stabilize particular "surfaces" of intracellular receptors that alter their interactions with chromosomal response elements and effect differential gene regulation. Specifically, our series of arylpyrazole compounds are valuable tools for dissection of cellular and molecular functions of GR. For example, detailed analyses of ligand-specific regulatory complexes at distinct GREs will advance our understanding of the context-dependence that contributes to the remarkable range of physiological actions of GR and other intracel- 
lular receptors. Moreover, these compounds may provide a potential resource for therapeutic development.

\section{Materials and methods}

qPCR

Total RNA was isolated from cells by using QIAshredder and RNeasy kits (Qiagen). To synthesize random-primed cDNA, 0.5 $\mu \mathrm{g}$ of total RNA $(10 \mu \mathrm{L}), 4 \mu \mathrm{L}$ of $2.5 \mathrm{mM}$ dNTP, and $2 \mu \mathrm{L}$ of random primers (New England Biolabs) were mixed and incubated at $70^{\circ} \mathrm{C}$ for $10 \mathrm{~min}$. A $4-\mu \mathrm{L}$ cocktail containing $25 \mathrm{U}$ of Moloney Murine Leukemia Virus (M-MuLV) Reverse Transcriptase (New England Biolabs), $10 \mathrm{U}$ of RNasin (Promega), and $2 \mu \mathrm{L}$ of 10x reaction buffer (New England Biolabs) was then added, and incubated at $42^{\circ} \mathrm{C}$ for $1 \mathrm{~h}$. The reaction was then incubated at $95^{\circ} \mathrm{C}$ for $5 \mathrm{~min}$.

The resultant cDNA was diluted to $200 \mu \mathrm{L}$, and $4-5 \mu \mathrm{L}$ was used per $35-\mu \mathrm{L}$ reaction containing $1.25 \mathrm{U}$ of TaqDNA polymerase (Promega), $1 \times$ reaction buffer, $1.5 \mathrm{mM} \mathrm{MgCl}_{2}, 0.5 \mathrm{mM} \mathrm{dNTP}$ (Invitrogen), 0.2× SYBR green I dye (Molecular Probes), and 357 $\mathrm{nM}$ each primer. qPCR was performed in an Opticon-2 DNA Engine (MJ Research) and analyzed by using the Ct method (Applied Biosystems Prism 7700 Users Bulletin No. 2) and Rpl19 as an internal control for data normalization.

For ChIP experiments, samples from $1 \times 10^{8}$ to $2 \times 10^{8}$ A549 cells were used for $40 \mathrm{qPCR}$ reactions. Primers that correspond to the promoter region of the hsp70 gene were used for data normalization.

All primers used in this report are available upon request.

\section{ChIP}

A549 cells $\left(1 \times 10^{8}\right.$ to $2 \times 10^{8}$ cells $)$ were cross-linked by adding $10 \%(\mathrm{v} / \mathrm{v})$ of a formaldehyde stock solution $(50 \mathrm{mM}$ HEPES$\mathrm{KOH}$ at $\mathrm{pH} 8 ; 1 \mathrm{mM}$ EDTA; $0.5 \mathrm{mM}$ EGTA; $100 \mathrm{mM} \mathrm{NaCl}$; $4.1 \%$ formaldehyde) at room temperature for $10 \mathrm{~min}$. After 5 min, $0.125 \mathrm{M}$ glycine (final concentration) was added to stop the cross-linking, cells were rinsed with phosphate-buffered saline (PBS), harvested by scraping, and collected by centrifugation (5 $\mathrm{min}$ at $600 \mathrm{~g})$. Pellets were resuspended in Lysis Buffer $(50 \mathrm{mM}$ HEPES-KOH at $\mathrm{pH} 8 ; 1 \mathrm{mM}$ EDTA; $0.5 \mathrm{mM}$ EGTA; $140 \mathrm{mM}$ $\mathrm{NaCl} ; 10 \%$ glycerol; $0.5 \%$ NP-40; $0.25 \%$ Triton X-100; $1 \mathrm{mM}$ PMSF; $5 \mu \mathrm{g} / \mathrm{mL}$ each of leupeptin, pepstatin A, and aprotinin) and nutated for $10 \mathrm{~min}$ at $4^{\circ} \mathrm{C}$. The crude nuclei were collected by centrifugation $\left(600 \mathrm{~g}\right.$ for $5 \mathrm{~min}$ at $\left.4^{\circ} \mathrm{C}\right)$ and resuspended in Wash Buffer (10 mM Tris- $\mathrm{HCl}$ at $\mathrm{pH} 8 ; 1 \mathrm{mM}$ EDTA; $0.5 \mathrm{mM}$ EGTA; $200 \mathrm{mM} \mathrm{NaCl} ; 1 \mathrm{mM} \mathrm{PMSF} ; 5 \mu \mathrm{g} / \mathrm{mL}$ each of leupeptin, pepstatin $\mathrm{A}$, and aprotinin) and nutated again. Washed nuclei were centrifuged as above and resuspended in $1 \times$ RIPA Buffer $(10$ $\mathrm{mM}$ Tris- $\mathrm{HCl}$ at $\mathrm{pH} 8 ; 1 \mathrm{mM}$ EDTA; $0.5 \mathrm{mM}$ EGTA; $140 \mathrm{mM}$ $\mathrm{NaCl}_{1} 1 \%$ Triton X-100; $0.1 \%$ Na-deoxycholate; $0.1 \%$ SDS; 1 $\mathrm{mM}$ PMSF; $5 \mu \mathrm{g} / \mathrm{mL}$ each of leupeptin, pepstatin A, and aprotinin).

Samples were sonicated (power setting 5-6) with a Branson Sonifier 250 with a microtip in 20 -sec bursts followed by $1 \mathrm{~min}$ of cooling on ice for a total sonication time of 120-150 sec per sample. This procedure produced DNA fragment sizes of $0.3-$ $0.8 \mathrm{~kb}$. Samples were then centrifuged in a microfuge at maximal speed for $10 \mathrm{~min}$ at $4^{\circ} \mathrm{C}$. N499 antibody raised against GR (Nissen and Yamamoto 2000) or AcH3 or AcH4 antibody (Upstate) was added to this cleared chromatin extract and incubated overnight with rotation at $4^{\circ} \mathrm{C}$. Samples were then centrifuged again, and supernatants were transferred to fresh tubes containing $20 \mu \mathrm{L}$ of precleared 50\% slurry Protein A/G agarose beads (for GR, Santa Cruz) or Protein A agarose beads (for AcH3 and $\mathrm{AcH} 4$, Upstate) in $1 \times$ RIPA containing $100 \mu \mathrm{g} / \mathrm{mL}$ sonicated salmon sperm DNA. After $3 \mathrm{~h}$ with beads, samples were centrifuged and the pellets were washed once with $1 \times$ RIPA buffer, three times with $1 \times$ RIPA containing $100 \mu \mathrm{g} / \mathrm{mL}$ salmon sperm DNA for 5 min with rotation, twice with $1 \times$ RIPA containing $500 \mathrm{mM} \mathrm{NaCl}$ final plus $100 \mu \mathrm{g} / \mathrm{mL}$ salmon sperm DNA for 5 min with rotation, and once with $1 \times$ RIPA buffer. Then $100 \mu \mathrm{L}$ of digestion buffer was added ( $50 \mathrm{mM}$ Tris at $\mathrm{pH} 8 ; 1 \mathrm{~mm}$ EDTA; $100 \mathrm{mM} \mathrm{NaCl} ; 0.5 \%$ SDS; $100 \mu \mathrm{g} / \mathrm{mL}$ proteinase $\mathrm{K}$ ) and placed at $55^{\circ} \mathrm{C}$ for $3 \mathrm{~h}$, followed by overnight at $65^{\circ} \mathrm{C}$ to reverse crosslinks. DNA was phenol- $\mathrm{CHCl}_{3}$ extracted once, $\mathrm{CHCl}_{3}$ extracted once, and ethanol precipitated in the presence of $20 \mu \mathrm{g}$ of glycogen. Pellets were resuspended in TE and used to perform qPCR.

\section{Cell lines}

A549 human lung adenocarcinoma cells (ATCC and UCSF cell cultural facility) were cultured in DMEM with $10 \%$ fetal bovine serum (FBS; GIBCO). When cells were treated with dexamethasone, prednisolone, or arylpyrazole compounds, DMEM with $10 \%$ charcoal stripped FBS (Omega) was used.

3T3-L1 preadipocytes (ATCC) were cultured in DMEM with $10 \%$ calf serum (GIBCO). Confluent cultures were induced to differentiate by changing the medium to DMEM with $10 \%$ FBS, $1 \mu \mathrm{g} / \mathrm{mL}$ insulin, $0.5 \mathrm{mM}$ isobutyl-1-methylzanthin, and $1 \mu \mathrm{M}$ dexamethasone, prednisolone, or distinct arypyrazole compounds. After $2 \mathrm{~d}$, this medium was replaced with DMEM supplemented with $10 \%$ FBS plus $1 \mu \mathrm{g} / \mathrm{mL}$ insulin, and cells were maintained in this medium until processing for analysis.

MC3T3-E1 cells (a gift of Dr. Tamara Alliston, University of California at San Francisco, San Francisco, CA) were grown in $\alpha$-MEM with $10 \%$ FBS. For osteoblast differentiation, these cells were switched to differentiation medium upon reaching confluence. This medium consisted of $\alpha$-MEM, $10 \%$ FBS, $100 \mathrm{mg} / \mathrm{mL}$ ascorbic acid, and $5 \mathrm{mM} \beta$-glycerophosphate.

\section{Cell viability assay}

Cell viability was monitored using the CellTiter-GloTM luminescence assay (Promega) according to the manufacturer's recommended protocols. This assay uses luciferase to measure ATP, an indicator of viable cells. The luminescent signal produced is proportional to the number of viable cells present in culture.

\section{Oil Red O staining}

3T3-L1 cells were washed three times with PBS and fixed in $10 \%$ formalin in PBS for $1 \mathrm{~h}$. After washing the cells twice with PBS, cells were stained with Oil Red staining solution $10.5 \%$ Oil Red [Sigma] in isopropanol, diluted 3:2 in water and filtered with a $0.22-\mu \mathrm{m}$ filter). After staining, cells were washed three times with water. Isopropanol was then added into culture wells for $15 \mathrm{~min}$. The extracting dye was monitored at the optical density $500 \mathrm{~nm}$ (Janderova et al. 2003).

\section{Alizarin red staining}

Confluent cultures of MC3T3-E1 cells in 12-well plates were rinsed in $\mathrm{Ca}^{2+} / \mathrm{Mg}^{2+}$-free phosphate-buffered saline and fixed for $5 \mathrm{~min}$ in $10 \%$ formalin/saline. The cells were then incubated with alizarin red $(0.1 \%$ in saline) solution for 3-7 min followed by several washes with water. For quantitation, the stained cells were destained for 3-4 h with ethylpyridinium chloride (Sigma), 
and the extracted stain was measured by absorbance at $562 \mathrm{~nm}$ (Stanton et al. 2004).

\section{GR-GFP cell line and imaging analysis}

The eGFP-rGR cell line expressing enhanced GFP-rat GR under control of the Tet-Off synthetic promoter was obtained as a stably transfected derivative of the Tet-Off murine mammary adenocarcinoma cell line 5858 (Rayasam et al. 2005). The eGFPrGR construct was cloned into pTRE-tight (Clontech), and the resulting construct was transfected along with a puromycinresistance plasmid into Tet-Off cell line 5858. Colonies were selected in media supplemented with $1.5 \mu \mathrm{g} / \mathrm{mL}$ puromycin and isolated by single-cell cloning of strongly GFP-positive cells. Cells were maintained in DMEM (GIBCO) supplemented with $10 \%$ FBS, $0.1 \mathrm{mM}$ nonessential amino acids, $2 \mathrm{mM}$ L-glutamine, $1 \mathrm{mM}$ sodium pyruvate, $1 \mathrm{mg}$ of $\mathrm{G} 418 / \mathrm{mL}, 1.5 \mu \mathrm{g} / \mathrm{mL}$ puromycin, and $10 \mu \mathrm{g} / \mathrm{mL}$ tetracycline at $37^{\circ} \mathrm{C}$ in $5 \% \mathrm{CO}_{2}$ in a humidified incubator. To induce eGFP-rGR expression for imaging, cells were transferred to Lab-Tek II chambers (Nalge Nunc International) $3 \mathrm{~d}$ prior to imaging and grown in media without tetracycline. One day prior to imaging, cells were switched to phenol red-free DMEM supplemented with $0.1 \mathrm{mM}$ nonessential amino acids, $2 \mathrm{mM}$ L-glutamine, $1 \mathrm{mM}$ sodium pyruvate, 1 $\mathrm{mg}$ of $\mathrm{G} 418 / \mathrm{mL}, 1.5 \mu \mathrm{g} / \mathrm{mL}$ puromycin, and $10 \mu \mathrm{g} / \mathrm{mL}$ tetracycline, and with $10 \%$ charcoal-stripped FBS (Omega). Cells were treated with ligand $(1 \mu \mathrm{M})$ for $4 \mathrm{~h}$ before imaging using a Zeiss Axiovert 200M microscope with a Zeiss Apochromat 63×/1.4numerical-aperture oil immersion objective.

\section{Transfection}

Transfection of A549 lung adenocarcinoma cells used lipofectamine 2000 (Invitrogen) according to the technical manual; cells were harvested $24 \mathrm{~h}$ post-transfection. Assays for $\beta$-galactosidase and luciferase activity have been described previously (Iniguez-Lluhi et al. 1997). The TAT3 reporter plasmid was previously described (Iniguez-Lluhi et al. 1997).

\section{Ligand-binding assays}

Ligand binding was determined by fluorescence polarization using GR, AR, and PR Competitor Assay Kits (Invitrogen) according to the manufacturer's recommended protocol (Shah and Scanlan 2004).

\section{Acknowledgments}

We thank Drs. Lisa Choy, Tamara Alliston, and Fred Schaufele for providing MC3T3-E1 preosteoblasts and 3T3-L1 preadipocytes. We thank Drs. Rik Derynck, Brian Black, Kevan Shokat, Hans Luecke, Eric Bolton, Neal Freedman, and Inez Rogatsky for reviewing the manuscript. J.-C.W. is supported by a postdoctoral fellowship of the American Heart Association. S.H.M. is supported by a post-doctoral fellowship from the Leukemia and Lymphoma Society. C.P. is supported by a predoctoral fellowship from the American Heart Association. This work is supported by grants from the NIH to K.R.Y. and T.S.S.

\section{References}

Alheim, K., Corness, J., Samuelsson, M.K., Bladh, L.G., Murata, T., Nilsson, T., and Okret, S. 2003. Identification of a functional glucocorticoid response element in the promoter of the cyclin-dependent kinase inhibitor p57Kip2. J. Mol. Endocrinol. 30: 359-368.

Chow, Y.H., Wang, Y., Plumb, J., O'Brodovich, H., and Hu, J. 1999. Hormonal regulation and genomic organization of the human amiloride-sensitive epithelial sodium channel $\alpha$ subunit gene. Pediatr. Res. 46: 208-214.

Crouch, S.P., Kozlowski, R., Slater, K.J., and Fletcher, J. 1993. The use of ATP bioluminescence as a measure of cell proliferation and cytotoxicity. J. Immunol. Methods 160: 81-88.

Diamond, M.I., Miner, J.N., Yoshinaga, S.K., and Yamamoto, K.R. 1990. Transcription factor interactions: Selectors of positive or negative regulation from a single DNA element. Science 249: 1266-1272.

Downes, M., Verdecia, M.A., Roecker, A.J., Hughes, R., Hogenesch, J.B., Kast-Woelbern, H.R., Bowman, M.E., Ferrer, J.L., Anisfeld, A.M., Edwards, P.A., et al. 2003. A chemical, genetic, and structural analysis of the nuclear bile acid receptor FXR. Mol. Cell 11: 1079-1092.

Iniguez-Lluhi, J.A., Lou, D.Y., and Yamamoto, K.R. 1997. Three amino acid substitutions selectively disrupt the activation but not the repression function of the glucocorticoid receptor $\mathrm{N}$ terminus. J. Biol. Chem. 272: 4149-4156.

Ito, K., Barnes, P.J., and Adcock, I.M. 2000. Glucocorticoid receptor recruitment of histone deacetylase 2 inhibits interleukin-1 $\beta$-induced histone $\mathrm{H} 4$ acetylation on lysines 8 and 12. Mol. Cell. Biol. 20: 6891-6903.

Janderova, L., McNeil, M., Murrell, A.N., Mynatt, R.L., and Smith, S.R. 2003. Human mesenchymal stem cells as an in vitro model for human adipogenesis. Obes. Res. 11: 65-74.

Jordan, V.C. 2004. Selective estrogen receptor modulation: Concept and consequences in cancer. Cancer Cell 5: 207-213.

Kian Tee, M., Rogatsky, I., Tzagarakis-Foster, C., Cvoro, A., An, J., Christy, R.J., Yamamoto, K.R., and Leitman, D.C. 2004. Estradiol and selective estrogen receptor modulators differentially regulate target genes with estrogen receptors $\alpha$ and B. Mol. Biol. Cell 15: 1262-1272.

Leclerc, N., Luppen, C.A., Ho, V.V., Nagpal, S., Hacia, J.G., Smith, E., and Frenkel, B. 2004. Gene expression profiling of glucocorticoid-inhibited osteoblasts. J. Mol. Endocrinol. 33: 175-193.

Lefstin, J.A. and Yamamoto, K.R. 1998. Allosteric effects of DNA on transcriptional regulators. Nature 392: 885-888.

Leung, T.H., Hoffmann, A., and Baltimore, D. 2004. One nucleotide in a $\mathrm{\kappa B}$ site can determine cofactor specificity for NF-кB dimers. Cell 118: 453-464.

Luecke, H.F. and Yamamoto, K.R. 2005. The glucocorticoid receptor blocks $\mathrm{P}-\mathrm{TEFb}$ recruitment by NFKB to effect promoter-specific transcriptional repression. Genes \& Dev. 19: $1116-1127$.

Luppen, C.A., Leclerc, N., Noh, T., Barski, A., Khokhar, A., Boskey, A.L., Smith, E., and Frenkel, B. 2003. Brief bone morphogenetic protein 2 treatment of glucocorticoid-inhibited MC3T3-E1 osteoblasts rescues commitment-associated cell cycle and mineralization without alteration of Runx2. J. Biol. Chem. 278: 44995-45003.

Miner, J.N. and Yamamoto, K.R. 1991. Regulatory crosstalk at composite response elements. Trends Biochem. Sci. 16: 423426.

Nissen, R.M. and Yamamoto, K.R. 2000. The glucocorticoid receptor inhibits NFKB by interfering with serine- 2 phosphorylation of the RNA polymerase II carboxy-terminal domain. Genes \& Dev. 14: 2314-2329.

Perretti, M., Chiang, N., La, M., Fierro, I.M., Marullo, S., Getting, S.J., Solito, E., and Serhan, C.N. 2002. Endogenous lipid- and peptide-derived anti-inflammatory pathways generated with glucocorticoid and aspirin treatment activate 
the lipoxin A4 receptor. Nat. Med. 8: 1296-1302.

Rayasam, G.V., Elbi, C., Walker, D.A., Wolford, R., Fletcher, T.M., Edwards, D.P., and Hager, G.L. 2005. Ligand-specific dynamics of the progesterone receptor in living cells and during chromatin remodeling in vitro. Mol. Cell. Biol. 25: 2406-2418.

Rogatsky, I., Wang, J.C., Derynck, M.K., Nonaka, D.F., Khodabakhsh, D.B., Haqq, C.M., Darimont, B.D., Garabedian, M.J., and Yamamoto, K.R. 2003. Target-specific utilization of transcriptional regulatory surfaces by the glucocorticoid receptor. Proc. Nat1. Acad. Sci. 100: 13845-13850.

Rosen, J. and Miner, J.N. 2005. The search for safer glucocorticoid receptor ligands. Endocr. Rev. 26: 452-464.

Roviezzo, F., Getting, S.J., Paul-Clark, M.J., Yona, S., Gavins, F.N., Perretti, M., Hannon, R., Croxtall, J.D., Buckingham, J.C., and Flower, R.J. 2002. The annexin-1 knockout mouse: What it tells us about the inflammatory response. J. Physiol. Pharmacol. 53: 541-553.

Schacke, H., Docke, W.D., and Asadullah, K. 2002. Mechanisms involved in the side effects of glucocorticoids. Pharmacol. Ther. 96: 23-43.

Schafer, S.C., Wallerath, T., Closs, E.I., Schmidt, C., Schwarz, P.M., Forstermann, U., and Lehr, H.A. 2005. Dexamethasone suppresses eNOS and CAT-1 and induces oxidative stress in mouse resistance arterioles. Am. I. Physiol. Heart Circ. Physiol. 288: H436-H444.

Shah, N. and Scanlan, T.S. 2004. Design and evaluation of novel nonsteroidal dissociating glucocorticoid receptor ligands. Bioorg. Med. Chem. Lett. 14: 5199-5203.

Shang, Y. and Brown, M. 2002. Molecular determinants for the tissue specificity of SERMs. Science 295: 2465-2468.

Stafford, J.M., Wilkinson, J.C., Beechem, J.M., and Granner, D.K. 2001. Accessory factors facilitate the binding of glucocorticoid receptor to the phosphoenolpyruvate carboxykinase gene promoter. J. Biol. Chem. 276: 39885-39891.

Stanton, L.A., Sabari, S., Sampaio, A.V., Underhill, T.M., and Beier, F. 2004. p38 MAP kinase signalling is required for hypertrophic chondrocyte differentiation. Biochem. I. 378: 53-62.

Wallerath, T., Witte, K., Schafer, S.C., Schwarz, P.M., Prellwitz, W., Wohlfart, P., Kleinert, H., Lehr, H.A., Lemmer, B., and Forstermann, U. 1999. Down-regulation of the expression of endothelial NO synthase is likely to contribute to glucocorticoid-mediated hypertension. Proc. Natl. Acad. Sci. 96: 13357-13362.

Wallerath, T., Godecke, A., Molojavyi, A., Li, H., Schrader, J., and Forstermann, U. 2004. Dexamethasone lacks effect on blood pressure in mice with a disrupted endothelial NO synthase gene. Nitric Oxide 10: 36-41.

Wang, H.C., Zentner, M.D., Deng, H.T., Kim, K.J., Wu, R., Yang, P.C., and Ann, D.K. 2000. Oxidative stress disrupts glucocorticoid hormone-dependent transcription of the amiloridesensitive epithelial sodium channel $\alpha$-subunit in lung epithelial cells through ERK-dependent and thioredoxin-sensitive pathways. J. Biol. Chem. 275: 8600-8609.

Wang, J.C., Derynck, M.K., Nonaka, D.F., Khodabakhsh, D.B., Haqq, C., and Yamamoto, K.R. 2004. Chromatin immunoprecipitation (ChIP) scanning identifies primary glucocorticoid receptor target genes. Proc. Natl. Acad. Sci. 101: 1560315608.

Yamamoto, K.R. 1985. Steroid receptor regulated transcription of specific genes and gene networks. Annu. Rev. Genet. 19: 209-252.

. 1995. Multilayered control of intracellular receptor function. Harvey Lect. 91: 1-19. 


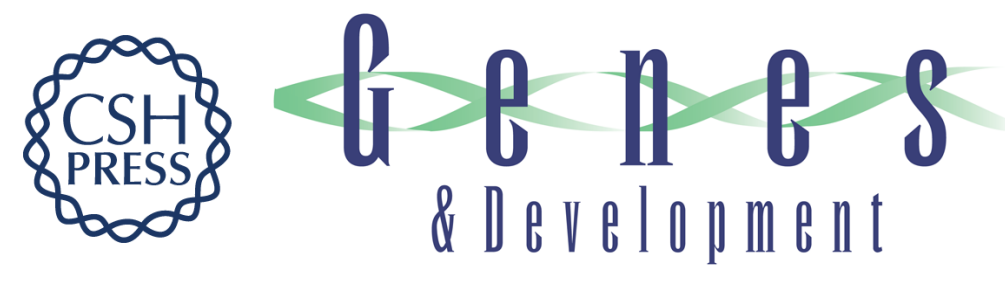

\section{Novel arylpyrazole compounds selectively modulate glucocorticoid receptor regulatory activity}

Jen-Chywan Wang, Nilesh Shah, Carlos Pantoja, et al.

Genes Dev. 2006, 20:

Access the most recent version at doi:10.1101/gad.1400506

Supplemental
Material http://genesdev.cshlp.org/content/suppl/2006/03/01/20.6.689.DC1

References This article cites 34 articles, 16 of which can be accessed free at: http://genesdev.cshlp.org/content/20/6/689.full.html\#ref-list-1

License

Email Alerting

Receive free email alerts when new articles cite this article - sign up in the box at the top Service right corner of the article or click here.

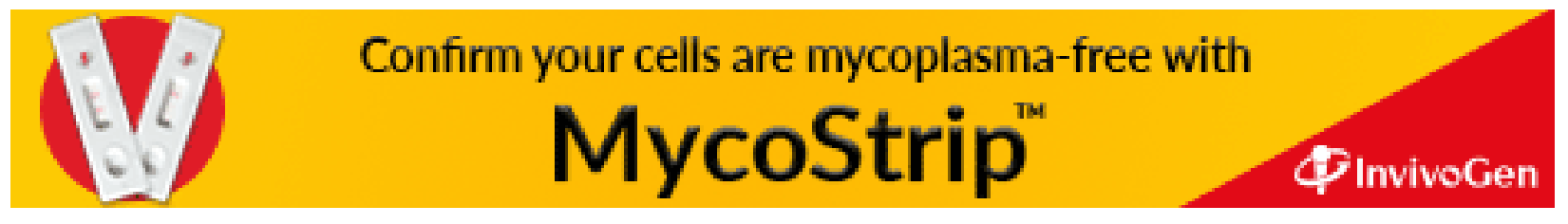

